\title{
Self-efficacy, Achievement motivation and Anxietyof Elite Athletes
}

\author{
Kenioua Mouloud ${ }^{1}$, Boumasjed Abd El-Kadder ${ }^{2}$ \\ ${ }^{1,2}$ Institute of physical education and sport, Mostaganem University, Algeria
}

\begin{abstract}
During the last few decades, coaches and athletes from a wide variety of sports have begun to realize the importance of mental side of athletic performance. Sport specialists agree that athletic performance is influenced not only by physical skills but also by psychological ones. this literature review has been touched three psychological characteristics athletes.
\end{abstract}

Keywords: self-efficacy, achievement motivation, anxiety, elite athletes.

\section{Introduction}

An elite athlete is a rare combination of talent, hard work and the right psychological profile. In sports today, everyone knows the best training methods, has access to the best facilities and most nutritional foods. Often the difference between the good and the elite is the mental qualities of the athletes. The focus of this paper is on three psychological characteristics athletes: self-efficacy, achievement motivation, and anxiety. More specifically, I wanted to look at what distinguishes an elite athlete from a sub-elite athlete in regards to these topics, and the relationship between these three characteristics.

\section{Self-efficacy}

Self-efficacy is posited as the basis for such conduct in the sense that it influences the strength of decisions, the quantity of energy invested in the effort, the level of perseverance in the face obstacles and failures or the resilience to adversity. In this sense, this psychological dimension is an individual resource to adapt to situations and contexts of activity grueling interesting sports psychology as the Health psychology and Occupational Psychology(decamps, 2012).

The concept of self-efficacy dates back several decades, and psychologist Albert Bandura was one of the first researchers exploring this topic. Bandura's (1977) theory of self-efficacy was developed within the framework of social cognitive theory. Although, originally, the theory was proposed to account for the different results achieved by diverse methods used in clinical psychology for the treatment of anxiety, it has since been expanded and applied to other domains of psychosocial functioning including health and exercise behavior (McAuley, 1992; McAuley \& Mihalko 1998; O'Leary, 1985), and sport and motor performance (Feltz, 1988). The reasons why athletes want to compete depend in the contrast between internal and external rewards as well as an athlete's preperformance assessment. In other words, if an athlete believes he or she can be successful, he or she is more likely to participate. In sport psychology, this is generally referred to as self-confidence or selfefficacy. High self-efficacy is judgment about one's capability to perform a particular task at an elevated level, with certainty, and repeatedly over time, athletes with higher self-efficacy tend to try harder, persist longer, choose greater challenges, experience effort more positively, and feel less anxious. NHL players who can picture winning a Stanley Cup, for example, will bust their butts come playoff time (and year-round, for that matter), but minor-league rookie who is enticed by a call-up for the postseason, yet thinks of himself as unready and cannot see himself competing with the "big boys", may be afraid to put his all on the line and may end up slacking off in practice (morphy, 2005). Self-efficacy is the belief in one's capabilities to organize and execute the source of action required to manage prospective situations (bandura, 1997). The concept of self-efficacy is vital to coaches, athletes, and even spectators, for several reasons. First, as a coach, knowing what athletes feel and think about their skills, abilities, and talents is important in the development of those characteristics. Second, a better understanding of an athlete's psyche can significantly improve the resulting sport performance (Moritz, Feltz, Fahrbach, \& Mack, 2000).

Many studies have touched on the self-efficacy and its relationship with some variables in sport in general and football in particular. A study conducted by Villani, Caputo, Balzarotti, and Riva (2015) on the enhancing self-efficacy through a blended training: A pilot study with basketball players, the results indicated that the athletes receiving the web-based interactive training reported higher levels of self-efficacy compared to the baseline assessment, while no significant differences emerged in the control group. Concerning emotion regulation, both groups reported less emotional suppression at the end of the training, while no significances emerged for cognitive reappraisal. However, cognitive reappraisal was associated with self-efficacy as measured before and after the intervention. Another study conducted by Zourbanos et.al (2016) on the Relationships 
Between Athletes' Perceptions of Coach-Created Motivational Climate, Self-Talk, and Self-Efficacy in Youth Football, the results showed that only positive and not negative self-talk mediated the relationship between empowering motivational climate and self-efficacy, whereas no relationship emerged between disempowering climate and self-efficacy, highlighting the role of self-talk explaining this relationship.A study conducted by Hazell, Cotterill, \& Hill (2014) on 20 male semi-professional soccer players. Players were tested on performance, anxiety, and self-efficacy, the results revealing a significant difference in somatic anxiety for the experimental group and a decrease in performance for the control group. And no significant interaction was found between the within-factor independent variable.

\section{Achievement motivation}

Whereas participation motivation is focused on why people decide to partake in sport, achievement motivation examines why, or why not, people may be motivated to achieve success, improve performance, master tasks and be good at their sport. Considering that success in sporting context is often assessed relative to opponents' performance, achievement motivation is often considered in relation to competitiveness. Competitiveness may be defined as the desire to reach a level of performance that is higher than others in the presence of evaluative others (Weinberg\& Gould, 2011). Achievement motivation is broader and focuses on athletes' predispositions towards striving for success and how specific situations influence their desires, emotions and behaviors (Tod, 2014).

The aim ofThe McClelland-Atkinson theory was to explain why some individuals are more motivated to achieve than others. The athlete's intrinsic motivation is seen as the motive to achieve. Acting against this intrinsic motivation, however, is the motive to avoid failure. when faced with a task such a sport, we face approach-avoidance conflict. We are motivated to approach and take part by our desire to succeed, but we are also motivated to avoid taking part by our desire to avoid failure.Our individual decision to participate in sport is determined by the relative strength of these two factors. This is shown in the following equation:

Achievement motivation $=$ desire to succeed - fear of failure (Atkinson, 1974; McClelland, 1961). To McClelland and Atkinson, achievement motivation is a personality trait. For some of us ,the desire to succeed far outweighs the fear of failure, and we are said to be high in achievement motivation .for others, the fear of failure is the more important factor, and they would de said to be low in achievement motivation .this personality trait is not the only factor that affects motivation. This situation is also important, specifically the probability of success and the incentive for success .thus, even if athletes are low in achievement motivation, if the probability of success is high, and the rewards for success are great, they are likely to be motivated (Jarvis, 2006).

The achievement motivation and performance has been studied extensively in the past many years. Study conducted by Feichtinger and Honer (2015) on talented football players' development of achievement motives, volitional components, and self-referential cognitions: a longitudinal study. The sample consists of 151 male players from the u 12to u14 age in the talent development programme of the German Football Association. The results showed Most of the personality characteristics' mean values differ significantly across the age classes with small effect sizes,conclusions are drawn regarding the talent identification and development process.Another study conducted by Soyer, Sari, and Talaghir (2014) on the relationship between perceived coaching behavior and achievement motivation: a research in football players. 123 male football players (X age $=20.16 \pm 2.96)$ voluntarily participated to the research. The results showed that level of education positively and significantly correlated with motive to approach success. The score of perceived leadership behaviors was dived into two categories (low and high score groups) in order to discover whether there is a difference between the high and low score groups with regard to achievement motivation score. Results of Mann Whitney U test indicated a significant difference in motive to avoid failure between the high and low score groups of training and instruction behavior, democratic behavior and social support behavior. The results suggest that there is a relationship between coaching behaviors and achievement motivation in football players. Study conducted by Yahyaoui (2009) on the attribution of success and failure and its relationship with the motivation of achievement in football players. The purpose of this study is to know the relationship between the attribution of success and failure with the sporting achievement motivation among the players of the national teams (under 17) from Algeria, Tunisia, Morocco and Libya. This study was based on a sample of 79 players under 17 (19 players of the Algerian national team, Tunisia: 21, Moroccan: 18 and the Libyan selection: 21). The tools used are represented by the sport Attribution Test and the Test of Achievement Motivation (directed by J.Willis). The results of this study show that players attribute much success or failure of internal sporting aspects over external aspects. A statistically significant difference was found between the Algerian national team with that of Tunisia (at the 0.05 level) regarding the award of good sportsmanship performance in favor of Algerian selection. In addition, a statistically significant difference was reported in the allocation of defeat between the Moroccan selection with that of Libya and Tunisia (at the 0.05 level) for the Moroccans. By cons, no significant differences were recorded between the players of the various national teams for the other parameters studied. 
Furthermore, a positive correlation was found between the attribution of success and achievement of success motivation, and the allocation between poor performance and motivation to avoid failure (at the 0.05 level) among players in our sample. However, no correlation was found between the other parameters studied.

\section{Anxiety}

Athletes and coaches often use the words "anxiety", "stress" and "arousal" interchangeably, and because their listeners generally know what they are trying to say it does not lead to miscommunication. Precision is needed. Anxiety refers to the levels of perceived threat that is accompanied by worry, nervousness and apprehension A key idea in anxiety is athletes' interpretation of the danger to their wellbeing. Sometimes anxiety is a normal response to real threats, such as when individuals are confronted by an armed person. Sometimes anxiety involves an exaggerated response to in imagined threat, such as my reaction to spiders (except in Australia where they can kill you!).Anxiety is typically accompanied by high arousal, but the two are not the same. People can be highly aroused yet not anxious, such as when athletes win major competitions (Tod, 2014).

Spielberger $(1966,1972)$ further noted that for a theory of anxiety to be an adequate it must differentiate as a mood state and as personality trait. additionally, it must differentiate among the stimulus conditions antecedent to these forms of anxiety. Spielberger(1966)proposed the state-trait theory of anxiety ,which differentiates between state and trait anxiety . State anxiety (A-state) is defined as an emotional state "characterized by subjective, consciously perceived feelings of apprehension and tension, accompanied by or associated with activation or arousal of the autonomic nervous system". This condition varies from moment to moment and fluctuates proportional to the perceived threat in the immediate situation. Trait anxiety (A-trait), on the other hand, is "a motive or acquired behavioral disposition that predisposes an individual to perceive a wide range of objectively non dangerous circumstances threatening and to respond to these with state anxiety reactions disproportionate in intensity to the magnitude of the objective danger". The state-trait theory of anxiety predicts that high-trait-anxious individuals will perceive more situations as threatening and react with greater state anxiety in a greater variety of situations than low-trait-anxious individuals.Adopting a multidimensional approach, Martens and colleagues (1990) proposed that cognitive anxiety, somatic anxiety and self confidence each had different relationships with performance.Performance was predicted to have a negative relationship with cognitive anxiety (increase in cognitive anxiety is associated with decrease in performance). Somatic anxiety was hypothesized to have an Inverted-U (Inverted-U theory 1908) relationship with performance. self-confidence was predicted to have a positive relationship with performance (increased selfconfidence is associated with improved performance).Along with proposing the multidimensional anxiety theory, Martens also published the Competitive State Anxiety Inventory-2(CSAI2) to help researchers test the model's predictions.

It is useful to differentiate between trait and state anxiety. In sport, competitive trait anxiety is a person's characteristic response or predisposition to perceive situations as threatening and to react with high anxiety. Competitive trait anxiety levels vary among athletes and influences state anxiety, or their right-now, moment -to moment perceptions of threat and accompanying worries and apprehension. Athletes with high levels of competitive trait anxiety are likely to respond to sporting events with high levels of state anxiety compared with participants with low trait levels the relationship in not perfect and state anxiety is also influenced by the situation. Athletes withhigh levels of trait anxiety will not respond to competitions with high state anxiousness if they do not view any threat to their wellbeing. Alternatively, athletes will low trait anxiety levels may experience high levels high state anxiety on occasions. It would be understandable, for example, if a low-trait athlete found a high-level event nerve-wracking, such as an Olympic final (Tod, 2014). Anxiety has a thought component (e.g., worry and apprehension)called cognitive anxiety. It also has a component called somatic anxiety .cognitive state anxiety concerns the degree to which one worries or has negative thoughts, whereas somatic state anxiety concerns the moment-to-moment changes in perceived physiological activation. Somatic state anxiety is not necessarily a change in one's physical activation but rather one's perception of such a change. Recent research also suggests that there is a perceived control or regulatory component of state anxiety ; that is ,the degree to which one believes one has the resources and ability to meet challenges is an important component of state anxiety as well (Cheng,Hardy,\& Markland,2009). The anxiety and performance relationship has been studied extensively in the past many years. Previous researches revealed that somatic and cognitive anxiety have different relationships with athletic performance. Athletic performance has been proven to facilitated by moderate levels of arousal while high and low levels of arousal are associated with lower levels of performance (Martens \& Landers,1970);Sonstroem \&Bemardo,1982;Wrisberg, Loberg ,\& Reed 2010). Concerning the relationship between cognitive anxiety and performance, research has found a negative relationship involving these variables. Higher levels of cognitive anxiety are associated with lower levels of performance (Burton, 1988; Motowildo, Packard, \&Manning, 1986). Klein (1990) by using the technique of meta-analysis concluded the negative relationship of anxiety and performance is: a) stronger in female athletes 
than male athletes, b) stronger in young athletes than in older athletes) stronger in low-level athletes and d) stronger in team than in individual sports. On the other hand self-confidence shows a positive linear relationship, while the relationship between somatic anxiety and performance has the shape of an inverted $\mathrm{U}$.

\section{Conclusion}

Performance accomplishments are the strongest source of self-efficacy, it stands to reason that these performance accomplishments enhance self-efficacy and that these increased feelings of self-efficacy then have a positive effect on subsequent performance. Hence, we see a reciprocal relationship between self-efficacy and performance. Interestingly, self-efficacy also allows individuals to overcome adverse experiences (e.g., suboptimalperformance) without any lasting damage to their sense of self. Achievement motivation is the tendency to strive for success, persist in the face of failure, and experience pride in accomplishments. Achievements motivation in sport exercise settings focuses on self-competition whereas competitiveness influences behavior in socially evaluative situations. Sate Anxiety is a temporary, ever-changing emotional state of subjective, consciously perceived feelings of apprehension and tension associated with activation of the autonomic nervous system. Trait anxiety is a behavioral disposition to perceive as threatening circumstance that objectively mat not be dangerous and to then respond with disproportionate state anxiety .people with high trait anxiety usually have more state anxiety in highly competitive, evaluate that do people with lower trait anxiety .

\section{Reference}

[1]. Bandura, A. (1977). Self-efficacy: Toward a unifying theory of behavioral change.psychological Review, 84(2), 191-215

[2]. Bandura, A. (1997).Self Efficacy. The Exercise of Control. New York: W.H. freeman.

[3]. Atkinson,J.W.(1974).the mainstream of achievement-oriented activity. In J.W.Atkinson \& J.O.Raynor (Ed.), motivation and achievement (pp.13-41). New York: Halstead.

[4]. McClelland,d.( 1961). The achieving society. New York: free press.

[5]. Martens, R.,Vealey,R.S. \& Buttoned.(1990). Competitive anxiety in sport. champaing,IL:Human Kinetics.

[6]. Martens, R. \& Landers, D. M. (1970). Motor performance under stress: A test of the Inverted-U hypothesis. Journal of Personality and Social Psychology, 16, 29-37.

[7]. Spielberger,C.D.(1966). Theory and research on anxiety. in C.D. Spielberger (Ed). Anxiety and behavior(pp.3-22). New York: academic press.

[8]. Spielberger,C.D.(1972). Anxiety as an emotional state. In C.D. Spielberger (Ed). Anxiety: current trends in theory and research (vl.1, pp.24-54). New York: academic press.

[9]. Cheng, W.K., Hardy,L.,\& Markland,D.(2009). Toward a three-dimensional conceptualization of performance anxiety:Rationale and initial measurement development. Psychology of sport and exercise, 10,271-278.

[10]. Decamps,G.(2012). Sport psychology andperformance (1st Ed).Brussels : groupe de boeck s.a ,p380.

[11]. Murphy,SH.(2005). The sport psych handbook. Champaign, IL:human kinetics ,(p8-9).

[12]. Feichtinger.p \& Höner. O. (2015): Talented football players' development of achievement motives, volitional components, and selfreferential cognitions: A longitudinal study.European Journal of sport Science, DOI:10.1080/17461391.2015.1051134.

[13]. Feltz, D. L. (1988). Self-confidence and sports performance. In K. B. Pandolf (Ed.) Exercise and Sport Sciences Reviews, (pp. 423457). New York: MacMillan.

[14]. Hazell.J.Cotterill, S.T.\& Hill. D. M. (2014). An exploration of pre-performance routines,self-efficacy, anxiety and performance in semi-professional soccer.European Journal of Sport Science, 14:6, 603-610, DOI:10.1080/17461391.2014.888484.

[15]. Jarvis, M. (2006). Sport psychology a student's handbook. (1st Ed.). New york ; Routledge,(141).

[16]. Klein, D. (1990). Anxiety and sport performance: A meta-analysis. Anxiety Research,2, 113-131.

[17]. McAuley, E. (1992). Self-referent thought in sport and physical activity. In T. S. Horn (Ed.), Advances in Sport Psychology, (pp. 101-118). Champaign, IL: Human Kinetics,

[18]. McAuley, E., \& Mihalko, S. L. (1998). Measuring exercise-related self-efficacy. In J. L.Duda (Ed.), Advancements in sport and exercise psychology measurement (pp. 371-390).Morgantown, WV: Fitness Information Technology.

[19]. Burton, D. (1988). Do anxious swimmers swim slower? Re-examining the elusive anxiety-performance relationship. Journal of Sports \& Exercise Psychology,10,45-61.

[20]. Mortiz,s.e.,Feltz, D.L.,Farhbach,.R.K.,\&Mack,D.E.(2000). The relation of self-efficacy measures to sport performance :A meta analysis review. Review quarterly for Exercise and sport, 71(11), 280-294.

[21]. Mortiz,s.e.,Feltz, D.L.,Farhbach,.R.K.,\&Mack,D.E.(2000). Tthe relation of self-efficacy measures to sport performance :A meta analysis review. Review quarterly for Exercise and sport, 71(11), 280-294.

[22]. O'Leary, A. (1985). Self-efficacy and health. Behavior Therapy and Research, 23, 437-452.

[23]. Soyer. F.,Sari. I.,and Talaghir.L.G. (2014).The relationship between perceived coaching behaviour and achievement motivation: a research in football players. Procedia - Social and Behavioral Sciences, pp.421 - 425. Published by Elsevier Ltd. This is an open access article under the CC BY-NC-ND license(http://creativecommons.org/licenses/by-nc-nd/3.0/).

[24]. Zourbanos, N., Haznadar, A., Papaioannou, A., Tzioumakis, Y., Krommidas, Ch., \& Hatzigeorgiadis, A. (2016). The Relationships Between Athletes' Perceptions of Coach-Created Motivational Climate, Self-Talk, and Self-Efficacy in Youth Football. Journal of Applied Sport Psychology, 28, 97-112. DOI:10.1080/10413200.2015.1074630

[25]. Tod,d.(2014).sport psychology the basics(1st Ed.). New York;Routledge, (p83-84).

[26]. Villani. D, Caputo. M, Balzarotti. S \& RivaG. (2015).Enhancing self-efficacy through a blended training: A pilot study with basketball players. International Journal of Sport and Exercise Psychology, http://dx.doi.org/10.1080/1612197X.2015.1079921.

[27]. Motowildo, S. J., Packard, J. S., \& Manning, M. R. (1986). Occupational stress: Its causes and con- sequences for job performance. Journal of Applied Psychology,71, 618-629.

[28]. Yahyaoui.S.(2009). Attribution of success and failure and its relationship with the motivation of achievement in football players, (sport study). unpublished p.h.d thesis, institute of Sport University of Algers.Algeria.

[29]. Wrisberg AC, Loberg A, Reed A (2010)"An exploratory investigation of NCAA division 1 coaches support of sport psychology consultant and willingness seek mutual training services".Sports Psychology 24, 489-503. 